\title{
Cloning and Expression in Escherichia coli of Clostridium stercorarium Strain F-9 Genes Related to Xylan Hydrolysis
}

\author{
Kazuo SaKKa, Yuzo KoJima, Kazuhiro YoshiKawa \\ and Kyo SHIMADA \\ Department of Bioscience, Faculty of Bioresources, \\ Mie University, Tsu 514, Japan \\ Received July 11, 1989
}

\begin{abstract}
Nine distinct fragments of Clostridium stercorarium strain F-9 (which was isolated and identified in this laboratory) DNA have been cloned in Escherichia coli and shown to express enzymatic activities related to xylan hydrolysis. Two of the $9 E$. coli clones showed xylanase activity, one showed $\beta$ xylosidase activity as well as xylanase activity, and the other 6 showed $\beta$-xylosidase activity. On comparing the restriction maps of the xylanase and xylosidase genes cloned in this study with those reported so far, it was concluded that all the 9 clones carried hitherto unidentified genes. All the enzymes expressed in the $E$. coli clones were thermophilic.
\end{abstract}

Xylan, which represents a major part of most plant cell walls, is second only to cellulose in natural abundance. This polymer consists of a $\beta$-1,4-xylopyranose chain, which commonly contains various constituent side groups ${ }^{1)}$. Recent interest in using biomass products as feedstock for chemicals and as biofuels has led to new research concerning the microbial degradation of xylans. The degradation of xylans requires a cadre of enzymes which attack the xylan backbone (xylanases and xylosidases), in addition to enzymes which remove various side chains. ${ }^{2)}$ Many bacteria have been reported to produce xylanase and xylosidase. ${ }^{3-9)}$ Furthermore, genes encoding xylanase and xylosidase have been cloned from several different microorganisms, including thermophilic clostridia. ${ }^{10-15}$ Thermophilic cellulases and their genes of Clostridium thermocellum are actively being investigated because of their high potential for the saccharification of the cellulosic biomass. A new anaerobic thermophilic bacterium, Clostridium stercorarium, ${ }^{16)}$ ferments hemicellulose and more carbohydrates than $C$. thermocellum. An endoglucanase $^{17)}$, a cellobiohydrolase ${ }^{18)}$ and 3 xylanases $^{19)}$ have been isolated from $C$.

\section{stercorarium.}

Recently, we succeeded in cloning several genes related to cellulose hydrolysis (endoglucanase, $\beta$-glucosidase and xylanase) from thermophilic Clostridium sp. strain $\mathrm{F} 1,{ }^{15)}$ but we could not isolate the $\beta$-xylosidase gene despite much effort. More recently, we attempted to clone the $\beta$-xylosidase gene in addition to the xylanase gene from another spore-forming anaerobic thermophilic bacterial strain, F-9, which was isolated, identified as $C$. stercorarium and shown to produce xylanase in this laboratory ${ }^{20}$. We have constructed a gene bank by ligating Sau3AI-digested strain F-9 chromosomal DNA into the BamH1 site of plasmid vector $\mathrm{pBR} 322$, and have screened for clones which hydrolyze xylan and 4-methylumbelliferyl- $\beta$-D-xylopyranoside (MUX). In this paper, we describe the cloning in $E$. coli of $C$. stercorarium F-9 genes coding for xylanase and $\beta$-xylosidase, as well as some properties of the enzymes expressed in E. coli.

\section{Materials and Methods}

Bacterial strains and plasmids. An anaerobic thermophilic bacterial strain, F-9, one of the bacteria isolated 
from compost by Furuse, ${ }^{20)}$ was used. The growth conditions were given previously. ${ }^{15}$ E. coli JM 109 was used as a recipient strain in transformation experiments. Plasmids pBR322 pUC118 and pUC119 were used as cloning vectors.

Isolation of chromosomal DNA and construction of the gene library. High-molecular-weight chromosomal DNA was isolated from strain F-9 as described previously ${ }^{15)}$ for Clostridium sp. strain F1. This DNA was partially digested with Sau3AI and fragments of 4 to $10 \mathrm{kbp}$ were isolated by agarose gel electrophoresis followed by electroelution. Libraries of these fragments were constructed by ligation into the dephosphorylated BamHl site of pBR322. E. coli JM109 was transformed with plasmid DNA. About 2500 clones with the ampicillin resistance $\left(A m p^{r}\right)$ and tetracycline sensitivity $\left(\mathrm{Tet}^{\mathrm{s}}\right)$ phenotypes were examined as to xylanase and xylosidase production.

Screening procedure. For the selection of xylanaseproducing (xylanase ${ }^{+}$) clones, LB-agar plates on which $E$. coli clones had been grown were exposed to chloroform vapour, air-dried, overlaid with $5 \mathrm{ml}$ of $\mathrm{PC}$ buffer $(50 \mathrm{~mm}$ $\mathrm{NaH}_{2} \mathrm{PO}_{4}-12 \mathrm{~mm}$ sodium citrate, $\mathrm{pH} 6.3$ ) containing $0.5 \%$ agar and $3 \%$ xylan, and then incubated at $60^{\circ} \mathrm{C}$ for several hours or overnight to allow the xylanase to produce a clear zone due to digestion of the turbid xylan suspension in the agar. For the selection of $\beta$-xylosidase-producing (xylosidase ${ }^{+}$) clones, $L B$-agar plates treated with chloroform as described above were overlaid with PC buffer containing $0.5 \%$ agar and $0.2 \%$ MUX, and then incubated at $60 \%$. Xylosidase $^{+}$clones were visualized as colonies within diffuse zones of blue-white fluorescence, due to the diffusion of the methylumbelliferon released through cleavage.

Construction of restriction maps. Single and double digestions of recombinant plasmids extracted from $E$. coli clones were carried out using restriction enzymes $B a m \mathrm{H} 1$, EcoRI, EcoRV, HindIII, PstI, Sall and SmaI. DNA fragments were fractionated by electrophoresis in $0.7 \%$ agarose gels and their sizes were estimated by referring to the migration of standards. Maps were built up from size data.

Enzyme assays. Recombinant E. coli clones were cultured overnight at $37^{\circ} \mathrm{C}$ in $5 \mathrm{ml}$ of LB medium on a rotary shaker. Cells were collected by centrifugation $(4000 \times g$, $4^{\circ} \mathrm{C}, 10 \mathrm{~min}$ ), washed once with $\mathrm{PC}$ buffer and then resuspended in $\mathrm{PC}$ buffer to $5 \mathrm{ml}$. The cell suspension was ultrasonicated (Ultrasonic Disruptor Model UR200P; Tomy Seiko Co., Ltd., Tokyo, Japan) for $90 \mathrm{sec}$ and then centrifuged for $10 \mathrm{~min}$ at $4000 \times g$ to remove unbroken cells. The cell-free extract obtained was used for enzyme assays. The protein concentration was determined by the method of Lowry et al. ${ }^{21)}$ with bovine serum albumin as a standard. Xylanase activity was assayed by incubation in
PC buffer for $10 \mathrm{~min}$ at $60^{\circ} \mathrm{C}$ in the presence of $0.7 \%$ xylan (oat-spelt; Fluka Ag, Buchs, Switzerland). Reducing sugars released from the substrate were assayed with the 3,5-dinitrosalicylic acid reagent as described by Borel $e t$ $a l^{22)}$ One unit of xylanase activity was defined as that which released $1 \mu \mathrm{mol}$ xylose equivalent per min from xylan. $\beta$-Xylosidase and $\beta$-glucosidase activities were assayed with $p$-nitrophenyl- $\beta$-D-xylopyranoside (PNPX) and $p$-nitrophenyl- $\beta$-D-glucoside (PNPG), respectively, at $60^{\circ} \mathrm{C}$. Enzyme activity against $p$-nitrophenyl- $\beta$-D-cellobioside (termed PNPCase) was also assayed at $60^{\circ} \mathrm{C}$. One unit of $\beta$-xylosidase, $\beta$-glucosidase and PNPCase activity, respectively, was defined as that which released $1 \mu \mathrm{mol}$ PNP per min from each substrate. Carboxymethylcellulase (CMCase) activity was assayed as described previously. ${ }^{15)}$ One unit of CMCase activity was defined as that which released $1 \mu \mathrm{mol}$ glucose equivalent per min from CMC.

\section{Results}

\section{Identification of the bacterium}

Strain F-9 was used as a DNA donor for the molecular cloning experiment, since it grew well on xylan as the sole carbon source and produced a large quantity of xylanase(s). The morphological and physiological characteristics of strain F-9 are summarized in Table I. Several species are described as thermophilic clostridia in the section of the genus

Table I. Characteristics of Strain F-9

\begin{tabular}{|c|c|c|}
\hline & Strain F-9 & C. stercorarium ** \\
\hline Shape & $\begin{array}{c}\operatorname{Rod} \\
(1 \times 3.5-5 \mu \mathrm{m})\end{array}$ & $\begin{array}{c}\text { Rod } \\
(0.7-0.8 \times 2.7-7.7)\end{array}$ \\
\hline Oxygen relationship & Anaerobe & Anaerobe \\
\hline Sporing & + & + \\
\hline Gram staining & - & - \\
\hline Motility & + & + \\
\hline $\begin{array}{l}\text { Optimal temperature } \\
\text { for growth } \\
\text { Growth on: }\end{array}$ & $60^{\circ} \mathrm{C}$ & $65^{\circ} \mathrm{C}$ \\
\hline glucose & + & + \\
\hline xylose & + & + \\
\hline cellobiose & + & + \\
\hline cellulose & + & + \\
\hline pectin & + & $\mathrm{ND}$ \\
\hline starch & + & + \\
\hline xylan & + & + \\
\hline $\mathrm{GC}$ content ${ }^{*}\left(\mathrm{~mol}^{\%} \%\right)$ & $38 \%$ & $39 \%$ \\
\hline
\end{tabular}

* The GC content was estimated from $T_{\mathrm{m}}$.

** These data were cited from ref. 16 .

$\mathrm{ND}$, no description in ref. 16 . 
Clostridium in Bergey's Manual of Systematic Bacteriology. ${ }^{16)}$ On the basis of the GC content, motility and ability to utilize carbohydrates such as xylose, xylan and starch for growth, this bacterium was identified as $C$. stercorarium.

\section{Construction and isolation of clones containing} strain F-9 xylanase or xylosidase genes

DNA fragments in the $4-10 \mathrm{kbp}$ size range were ligated to pBR322 as described under Materials and Methods. The ligation mixture was used to transform $E$. coli JM109 to Ampr.
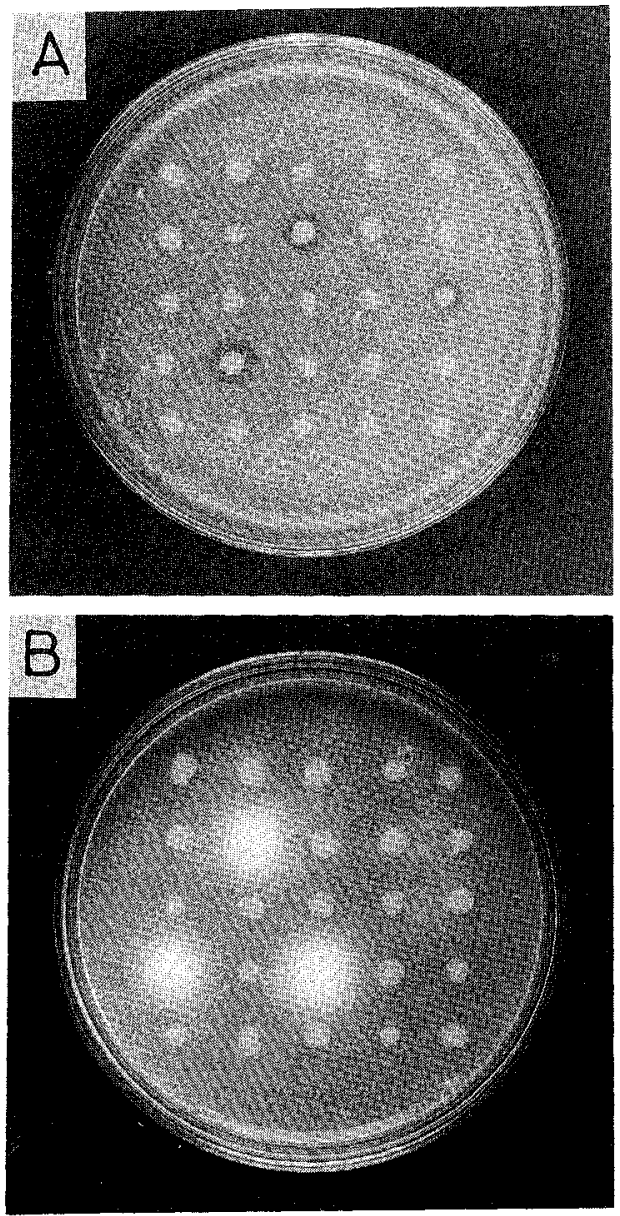

Fig. 1. Identification of Xylanase ${ }^{+}$and Xylosidase ${ }^{+}$ Clones of E. coli.

A: Xylanase ${ }^{+}$clones formed clear zones around their colonies.

B: Xylosidase ${ }^{+}$clones formed bright spots, which tended to diffuse.
About 2500 transformants with the Amp ${ }^{r}$ and $\mathrm{Tet}^{\mathrm{s}}$ phenotypes were screened for xylanase and xylosidase productivity by plate assays. Figure 1 shows typical of plate assays. Among the transformants, 9 clones (designated as YK201, YK202, YK203, YK204, YK205, YK206, YK208, YK209 and YK210) were selected as xylanase ${ }^{+}$clones, and 7 clones (designated as YK301, YK302, YK303, YK304, YK306, YK307 and YK308) were selected as xylosidase ${ }^{+}$clones. A clone designated as YK401 exhibited both activities in plate assays.

The plasmid was extracted from each clone and it was confirmed that each activity was cotransformed with the Amp ${ }^{r}$ character in $E$. coli JM109 at the frequency of $100 \%$.

\section{Characterization of recombinant plasmids}

On the basis of the agarose gel electrophoresis profiles of the recombinant plasmids digested with HindIII or Pst I, the 9 plasmids encoding xylanase were grouped into 2 classes, and the 7 plasmids encoding xylosidase were grouped into 6 classes. Finally, the restriction maps of 9 plasmids, i.e., pYK205, pYK208, pYK301, pYK303, pYK304, pYK306, pYK307, pYK308 and pYK401, were con-

Table II. EnZymatic ACtivities EXPRESSED by Recombinat Clones

\begin{tabular}{cccccc} 
& \multicolumn{5}{c}{ Specific activity (U/mg protein) } \\
\cline { 2 - 5 } Clone & \multicolumn{5}{c}{ Substrate hydrolyzed } \\
& Xylan & PNPX & CMC & PNPG & PNPC \\
\cline { 1 - 5 } YK205 & 0.75 & ND & -0.036 & ND & ND \\
YK208 & 17.27 & ND & 0.057 & ND & ND \\
YK301 & ND & 0.042 & ND & ND & ND \\
YK303 & ND & 0.047 & ND & 0.164 & 0.007 \\
YK304 & ND & 0.015 & - & ND & ND \\
YK306 & ND & 0.043 & ND & ND & ND \\
YK307 & ND & 0.005 & - & ND & ND \\
YK308 & ND & 0.103 & ND & ND & ND \\
YK401 & 8.16 & 0.009 & 2.10 & ND & 0.103 \\
\hline
\end{tabular}

Each clone was cultured overnight at $37^{\circ} \mathrm{C}$ in $\mathrm{LB}$ medium and then a cell-free extract was prepared as described under Materials and Methods.

ND, not detectable.

-, not tested. 


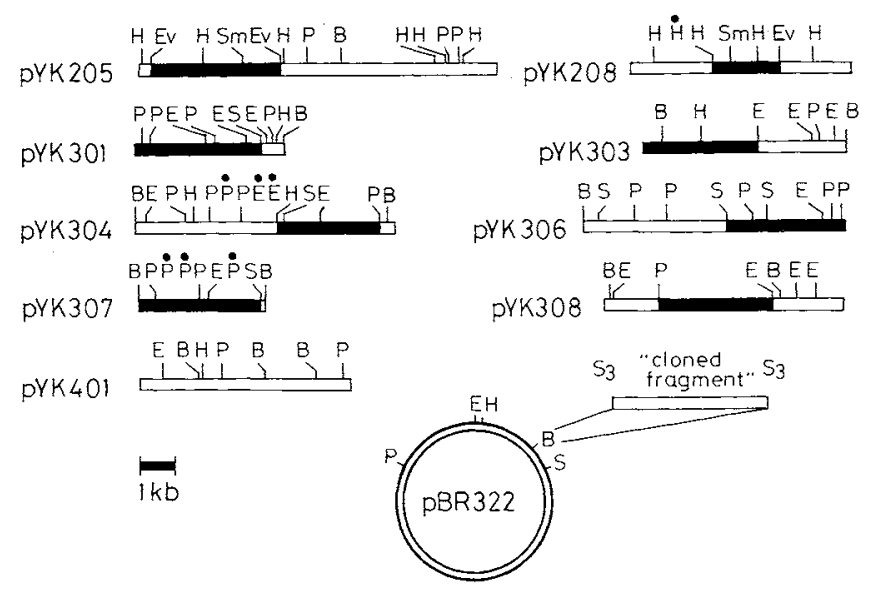

Fig. 2. Restriction Maps of DNA Fragments Encoding Xylanase and Xylosidase.

B, BamHI; E, EcoRI; Ev, EcoRV; H, HindIII; P, Pst I; S3, Sau3AI; Sm, SmaI. Plasmids were constructed by ligating strain F-9 chromosomal DNA digested with Sau3AI into the BamHI site of pBR322. The restriction sites denoted by $\dot{\mathrm{E}}, \dot{\mathrm{H}}$ and $\dot{\mathrm{P}}$ were not determined accurately. The regions where the genes have been delimitated by subcloning are solid black. Subcloning experiments were carried out using pUC118 or pUC119 as a vector.

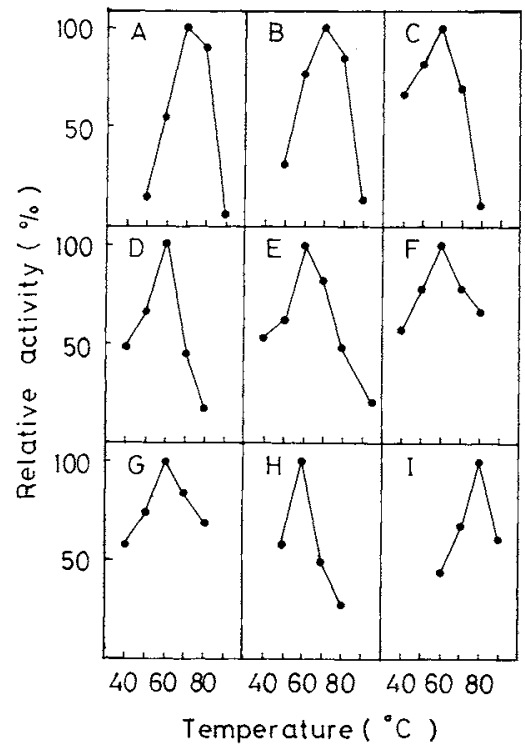

Fig. 3. Effect of Temperature on Enzyme Activity.

A, YK205; B, YK208; C, YK301; D, YK 303; E, YK304; F, YK 306; G, YK 307; H, YK308; I, YK401. The enzyme activities of YK205, YK208 and YK401 were assayed with xylan and those of the other clones were assayed with PNPX.

structed. As shown in Fig. 2, the restriction maps of the 9 recombinant plasmids differ from each other, indicating that each plasmid encodes a distinct gene. Restriction endonu- clease mapping indicated that the 9 plasmids contained $3.7-10.4 \mathrm{kbp}$ DNA inserts.

\section{Enzyme activity expressed by recombinant clones}

Cell-free extracts of the recombinant clones were assayed for various enzyme activities. The results are summarized in Table II. The enzymes produced by YK205 and YK208 hydrolyzed xylan but not PNPX at all. These enzymes showed low activity against $\mathrm{CMC}$. The enzymes produced by YK301, YK304, YK306, YK307 and YK308 hydrolyzed only PNPX among the substrates tested. The enzyme produced by YK303 hydrolyzed PNPX, PNPG and PNPC. The enzyme encoded by YK401 hydrolyzed xylan, PNPX and CMC. Analysis by paper chromatography revealed that all xylosidases hydrolyzed xylobiose.

The optimal temperature for each activity was determined. As shown in Fig. 3, all of the enzymes were thermophilic since they were derived from a thermophilic bacterium. The enzymes encoded by YK301, YK303, YK304, YK306, YK307 and YK308 were optimally active at $60^{\circ} \mathrm{C}$, which was identical to the optimal growth temperature of strain F-9. The enzyme encoded by YK401 showed a high 
optimal temperature $\left(80^{\circ} \mathrm{C}\right)$.

\section{Discussion}

In this study we constructed a gene bank from C. stercorarium strain F-9 and succeeded in cloning at least 9 genes involved in xylan hydrolysis. The enzymatic activities expressed by the recombinant clones were divided into 3 types; i) The enzymes encoded by YK205 and YK208 seem to be usual xylanases, which are active against xylan but not PNPX. ii) The enzymes encoded by YK301, YK303, YK 304, YK306, YK307 and YK308 are xylosidases which are not active against a highly polymerized substrate (xylan). Among these enzymes, the enzyme produced by YK303 had $\beta$-glucosidase activity as well as $\beta$-xylosidase activity. This enzyme gave the color of PNP from PNPC. This must be due to $\beta$-glucosidase activity since the rate of PNP liberation from PNPC was considerably lower than that of PNP liberation from PNPG. iii) The enzyme encoded by YK 401 showed both xylanase and xylosidase activities. Further, this enzyme hydrolyzed $\mathrm{CMC}$ without reducing the viscosity of the CMC solution, suggesting that this enzyme had exoglucanase activity (preliminary results). It is not known at present whether plural enzymatic activities conferred by a plasmid are due to a single enzyme, since the DNA fragment inserted in the vector plasmid seemed to be large enough to encode more than one protein.

Three endoxylanases, A, B and C, have been purified from $C$. stercorarium to homogeneity by SDS-polyacrylamide gel electrophoresis and shown to be inactive against PNPX by Berenger et $a .^{18)}$ The enzymes encoded by YK205 and YK208, which did not hydrolyze PNPX, might correspond to the enzymes described by them. Although the 9 xylanase $^{+}$ clones were originally selected by means of plate assays, they were grouped into only 2 classes. Seven plasmids other than pYK205 and pYK208 contained different DNA inserts, but restriction enzyme analysis indicated that the seven plasmids contained a region com- mon to the DNA insert of pYK208. It is possible that the $C$. stercorarium F-9 genome carried more than one copy of the xylanase gene contained in pYK208. Several xylanase genes were cloned from $C$. thermocellum and their restriction maps were published. ${ }^{15,23)} \mathrm{On}$ comparing the restriction maps of xylanase genes cloned in this study with those reported for $C$. thermocellum, it was concluded that pYK205 and pYK208 carried hitherto unidentified xylanase genes.

In the present study, we cloned $\beta$-xylosidase genes from a thermophilic Clostridium species for the first time and clarified that there are many different genes encoding $\beta$-xylosidase. On the other hand, we failed to isolate the $\beta$ xylosidase gene from another thermophilic strain, F1, which was unable to grow on xylan, when we successfully cloned 2 genes encoding xylanase activity. ${ }^{15)}$ This fact may suggest that the absence of the $\beta$-xylosidase gene is one of the possible causes of the inability of strain $\mathrm{F} 1$ to grow on xylan, and that each $\beta$-xylosidase plays an important role in the utilization of xylan by strain F-9. It would be interesting to investigate the substrate specificities and the modes of action of these enzymes since they might have different functions in the xylanolytic system of $C$. stercorarium strain F-9.

\section{References}

1) R. L. A. Whistler and E. L. Richards, in "The Carbohydrates," ed. by W. Pigman and D. Horton, Academic Press, New York, 1970, pp. 447-469.

2) K. K. W. Wong, L. U. L. Tan and J. N. Saddler, Microbiol. Rev., 52, 305 (1988).

3) P. A. D. Rickard and T. A. Laughlin, Biotechnol. Lett., 2, 363 (1980).

4) G. L. Pettipher and M. J. Latham, J. Gen. Microbiol., 110, 21 (1979).

5) R. Bernier, M. Desrochers, M. L. Jurasek and M. G. Paice, Appl. Environ. Microbiol., 46, 511 (1983).

6) C. W. Forsberg, T. J. Beveridge and Hellstrom, Appl. Environ. Microbiol., 42, 886 (1981).

7) W. Panbangred, A. Shinmyo, S. Kinoshita and H. Okada, Agric. Biol. Chem., 47, 957 (1983).

8) D. V. Garcia-Martinez, A. Shinmyo, A. Maida and A. L. Demain, Eur. J. Microbiol. Biotechnol., 9, 189 (1980).

9) S. F. Lee and C. W. Forseberg, Appl. Environ. 
Microbiol., 53, 651 (1987).

10) H. Moriyama, E. Fukusaki, J. C. Crespo, A. Shinmyo and H. Okada, Eur. J. Biochem., 166, 539 (1987).

11) M. G. Paice, R. Bourbonnais, M. Desrochers, L. Jurasek and M. Yaguchi, Arch. Microbiol., 144, 201 (1986).

12) A. Sipat, K. A. Taylor, R. Y. C. Lo, C. W. Forseberg and P. J. Krell, Appl. Environ. Microbiol., 53, 477 (1987).

13) G. W. Sewell, E. A. Utt, R. B. Hespell, K. F. Mackenzie and L. O. Ingram, Appl. Environ. Microbiol., 55, 306 (1989).

14) O. Grépinet, M. C. Chebrou and P. Béguin, $J$. Bacteriol., 170, 4582 (1988).

15) K. Sakka, S. Furuse and K. Shimada, Agric. Biol. Chem. 53, 905 (1989).

16) E. P. Cato, W. L. George and S. M. Finegold, in
"Bergey's Manual of Systematic Bacteriology," Vol. 2, Williams and Wilkins, Baltimore, Md., 1986, pp. $1141-1200$.

17) N. Creuzet and C. Frixon, Biochimie, 65, 149 (1983).

18) N. Creuzet, J. F. Bérenger and C. Frixon, FEMS Microbiol. Lett., 20, 347 (1983).

19) J. F. Bérenger, C. Frixon, J. Bigliardi and N. Creuzet, Can. J. Microbiol, 31, 635 (1985).

20) S. Furuse, Thesis for a Master's Degree, Mie Univ., 1986.

21) O. H. Lowry, N. J. Rosebrough, A. L. Farr and R. J. Randall, J. Biol. Chem., 193, 265 (1951).

22) E. Borel, F. Hotettler and H. Denel, Helv. Chim. Acta, 35, 115 (1952).

23) G. P. Hazlewood, M. P. H. Romaniec, K. Davidson, O. Grépinet, P. Béguin, J. Millet, O. Raynaud and J. P. Aubert, FEMS Microbiol. Lett., 51, 231 (1988). 